\title{
O MOVIMENTO RETÓRICO DAS INTRODUÇÕES DE ARTIGOS CIENTÍFICOS EM LÍNGUA ITALIANA
}

\author{
Patrícia Fabiana Bedran*
}

\begin{abstract}
RESUMO: A introdução de artigos cientificos vem sendo objeto constante de estudos de pesquisadores que buscam divulgar as instruções sobre o conteúdo linguístico bem com a estrutura argumentativa que compõe o discurso introdutório em uma tentativa de padronização, como podemos observar em Swales (2004), Duszak (1995) e Aranha (2006). Partindo dessa mesma perspectiva, objetivamos investigar as evidências linguísticas e a estrutura argumentativa em introduções desse gênero - artigo científico - em duas diferentes áreas do conhecimento: ornitologia e tecnologia, em uma língua ainda pouco explorada em pesquisas sobre gêneros, a italiana, a fim de verificar a aplicabilidade do modelo CARS (Creat a Research Space), proposto inicialmente por Swales (1997) e revisto por Aranha (2006). Os dados obtidos por meio dessa análise apontam que esse modelo é aplicável às introduções publicadas em língua italiana, mas que, por outro lado, a área do conhecimento exerce uma influência considerável nas escolhas linguísticas, na seleção e na organização dos movimentos e passos que configuram a constituição da introdução desses artigos.
\end{abstract}

PALAVRAS-CHAVE: gênero - movimentos e passos - introdução - italiano - modelo CARS (Creat a Research Space)

ABSTRACT: The introduction of scientific articles has been the constant object of study of researchers who seek to disseminate the instructions on the linguistic content as well as on the argumentative structure that makes up the introductory speech in an attempt to achieve an standardization, as observed in Swales (2004), Duszak (1995) and Aranha (2006). From this same perspective, we aim to investigate the linguistic evidences and the argumentative structure in introductions of the mentioned gender, scientific articles, in two different areas of knowledge: ornithology and technology in a language still little explored in researches on gender, Italian, in order to verify the applicability of the CARS model (Creat a Research Space), initially proposed by Swales (1997) and reviewed by Aranha (2006). The data obtained through this analysis show that this model is applicable to introductions published in Italian, but, on the other hand, the area of knowledge exerts considerable influence on the linguistic choices, selection and organization of movement and steps that constitute the introduction of these articles.

KEYWORDS: gender - movements and steps - introduction - Italian - CARS model (Creat a Research Space)

\section{INTRODUÇÃO}

Os gêneros vêm sendo objeto de pesquisas de vários estudiosos sob diversas perspectivas teóricas. Dentre eles destacamos os estudiosos do texto. Eles se manifestam por meio de textos, portanto, conhecer o seu funcionamento é indispensável

\footnotetext{
Aluna do programa de pós-graduação, curso de doutorado, da UNESP - Universidade Estadual Paulista, campus de São José do Rio Preto./ patriciabedran@yahoo.com.br.
}

Cadernos do IL. Porto Alegre, n. ${ }^{\circ}$ 38, junho de 2009. p. 108-129. 
para a produção bem como para a compreensão de ambos (gênero e texto), uma vez que, de acordo com a definição de Marcuschi (2002), gêneros, distantes de serem entidades naturais e prontas, são instáveis e (re)construídos histórica e socialmente.

No caso específico do ensino de línguas no terceiro grau, estudos como o de Motta-Roth (2009) indicam a necessidade do ensino da redação acadêmica de gêneros na universidade, uma vez que esta seria uma forma possível de assegurar $o$ comprometimento do aluno com a comunidade discursiva acadêmica. Dentre essas comunidades, destacamos aquela relacionada à produção de artigos científicos, de suma importância, já que o artigo científico é uma das formas de se divulgar os estudos e as pesquisas realizadas em meio acadêmico.

Partindo dessa necessidade do ensino de gêneros acadêmicos, embora não pretendamos abordar o processo de ensino e de aprendizagem de gêneros textuais que envolve outros fatores e não é o foco deste artigo, ressaltamos um primeiro passo que poderia facilitar o desempenho na língua escrita, que seria a compreensão de como a seção introdutória dos artigos científicos é organizada. Há, portanto, a nosso ver, uma necessidade de se analisar a organização da estrutura retórica das introduções, baseando-se em um modelo de operacionalização de introduções de artigos científicos, a fim de fornecer elementos facilitadores tanto para sua compreensão como para sua produção.

A escolha dessa seção artigo científico como objeto desta pesquisa se pauta principalmente na sua responsabilidade em fazer com que o leitor prossiga ou interrompa a leitura, o que justifica a crescente divulgação de instruções sobre o conteúdo linguístico bem como a estrutura argumentativa que compõem o discurso introdutório, em uma tentativa de padronização por parte dos pesquisadores (SWALES, 2004; ARANHA, 2007; DUSZAK, 1995).

Essa padronização não se remete apenas à estrutura e ao conteúdo da introdução, mas está associada também ao idioma - o inglês, pois há uma necessidade de se publicar em língua inglesa para que se possa fazer parte da comunidade científica acadêmica, manter-se atualizado com relação aos trabalhos realizados na comunidade e compartilhar resultados das pesquisas por meio da publicação, que é a base do avanço do conhecimento. Assim sendo, as pesquisas sobre a pertinência dos movimentos introdutórios se restringem, em grande parte, aos artigos publicados em língua inglesa.

Ainda que haja, embora em menor quantidade, publicações científicas de diferentes áreas em outras línguas, como a italiana, possivelmente por necessidade acadêmica, por restrição da comunidade discursiva e por falta de domínio da língua inglesa, o que justificaria a pertinência de estudos de aplicação de movimentos retóricos da introdução em outras línguas, que não a inglesa, desconhecemos estudos que tenham como objeto o italiano. Sendo assim, objetivamos investigar a construção da introdução de artigos científicos publicados por falantes nativos dessa língua em duas diferentes áreas de conhecimento: tecnologia e ornitologia, a fim de observar as diferentes formas como a introdução na atividade de cada campo, no que se refere às evidências linguísticas e estruturas argumentativas, baseando-nos no modelo de operacionalização proposto por Aranha (1996).

Cadernos do IL. Porto Alegre, n. ${ }^{\text {o } 38, ~ j u n h o ~ d e ~ 2009 . ~ p . ~ 108-129 . ~}$ http://www.seer.ufrgs.br/cadernosdoil/ 
Abordamos, ao longo deste artigo, o conceito de gênero, tecemos algumas considerações sobre a parte introdutória de artigos científicos bem como os movimentos retóricos e as evidências linguísticas características de introduções dos artigos selecionados. A seguir, relatamos a metodologia utilizada, apresentamos e discutimos, posteriormente, os resultados obtidos e, por fim, traçamos algumas considerações finais ressaltando as implicações desta pesquisa para o ensino de gêneros.

\title{
GÊNERO: DEFINIÇÕES E CARACTERÍSTICAS
}

Grande parte dos estudos sobre gêneros que utilizam seu conceito com finalidades pedagógicas pauta-se na definição de gênero de Swales (1990), que propõe um conceito eclético resultado de um entrelaçamento de ideias desenvolvidas em vários campos de estudo, a saber, folclorista, estudos literários, linguística e retórica. Para o autor, gêneros compreendem os eventos comunicativos, que estão relacionados ao discurso e seus participantes, ao papel desse discurso e seu ambiente de produção e recepção, aos propósitos comunicativos compartilhados (já que gêneros configuram-se como um veículo para atingir determinados objetivos) à variação do gênero em sua prototipicalidade, ao sistema inerente ao gênero que estabelece limitação às contribuições disponíveis em termos do seu conteúdo, posicionamento e forma e, por fim, à nomenclatura usada pelos membros da comunidade discursiva.

Os gêneros são concebidos como uma classe de eventos comunicativos, sóciohistoricamente (re)construídos, tendo em vista um objetivo a ser realizado por meio de um propósito comunicativo em comum. Assim sendo, gênero não depende apenas do nível linguístico, e, para compreendê-los, faz-se necessário entender como os textos se organizam informativa, retórica e estilisticamente (SWALES, 1990).

Outro aspecto importante a ser ressaltado que abarca a conceitualização de gênero é a distinção entre estudo do gênero e do texto apontada pelo autor. Muitas vezes, de maneira equivocada, associam-se ambos:

\begin{abstract}
Como o estudo do gênero é comumente identificado com a análise de textos, seria útil, inclusive, esclarecer que proponho ver gêneros mais do que como textos. Enquanto isso ainda é necessário para entender como os textos se organizam informativa, retórica e estilisticamente, o conhecimento textual permanece geralmente insuficiente para dar conta do gênero. (ibid., p. 6) ${ }^{1}$
\end{abstract}

A associação ocorre de maneira equivocada porque somente o conhecimento textual é insuficiente para o estudo do gênero, que não depende apenas do nível

\footnotetext{
${ }^{1}$ Since genre study is commonly identified with the analysis of texts, it would be useful, at an early juncture, to clarify that I propose to view genres as rather more than texts. While it remains necessary to use in order to understand how texts organize themselves informationally, rhetorically and stylistically, textual knowledge remains generally insufficient for a full account of genre (tradução nossa).
}

Cadernos do IL. Porto Alegre, n. ${ }^{o}$ 38, junho de 2009. p. 108-129. http://www.seer.ufrgs.br/cadernosdoil/ 
linguístico, mas também do textual discursivo, e, para reconhecê-lo, devemos atentar para sua finalidade, estatuto dos parceiros (para quem se diz algo), lugar e para sua organização textual.

Bathia (1993), que amplia o conceito de gênero proposto por Swales (1990), discorre sobre a estrutura interna que constitui um dado gênero, a qual é resultado de uma longa experiência por parte dos membros da comunidade discursiva que, embora tenham liberdade de escolhas linguísticas, necessariamente deveriam adequar-se às restrições impostas pelas regras e limites de cada gênero. Há, portanto, uma necessidade de compreensão do gênero e de suas macroestruturas retóricas, essenciais para que o falante de uma comunidade discursiva seja aceito e reconhecido como seu membro.

As realizações linguísticas dos propósitos comunicativos de determinados textos (ressaltamos aqui os artigos científicos, foco desta pesquisa) configuram-se por meio de abrangentes combinações possíveis e práticas da língua em uso, embora haja certa restrição quanto às escolhas textuais de acordo com o veículo de comunicação, ao público e à modalidade, seja ela oral ou escrita (ARANHA, 2007).

Embora o gênero seja permeado por certas regularidades, Marcuschi (2002), bem como Bazerman (2006), apontam para a dificuldade em se chegar a uma taxonomia, porque essa prática está associada ao formalismo redutor e à proposição de uma definição duradoura. No entanto, gêneros não são instrumentos estanques e enrijecedores da ação criativa, mas se caracterizam como eventos altamente maleáveis e dinâmicos, o que levou vários teóricos a conceituar gênero a partir de uma perspectiva sócio-histórica, como categorias culturalmente salientes e mutáveis.

Segundo Bazerman (2006, p. 49):

Tentativas de reforçar a uniformidade de gênero têm sido vistas sempre como restrições à criatividade e à expressão. $\mathrm{O}$ reconhecimento de cada leitor dos recursos especiais e pessoais num texto também parece fazer da formação de gênero, no máximo, um guia trivial para a interpretação. $O$ que está envolvido em qualquer designação de gênero, então, parece mudar de texto para texto, até o ponto em que não haja um conhecimento certo, histórico e culturalmente estável, que possamos obter de uma designação de gênero.

De acordo com o autor, o gênero existe a partir do momento em que os usuários o reconhecem, o distinguem e o interpretam. Nessa mesma perspectiva, Carvalho (2005) enfatiza a construção de gêneros, e acrescentamos (re)construção, com base na experiência sócio-retórica: propósitos comunicativos são estabelecidos e tenta-se alcançá-los, conferindo-lhes formas de percepção de semelhança entre a situação atual e outras análogas.

Distante de se desejar atingir uma taxonomia redutora ou caracterizar gêneros como simples objetos textuais semelhantes, gêneros são vistos por Swales (1990) como entidades sócio-historicamente construídas e compartilhadas pelos membros da comunidade em que ocorrem, os quais necessitam identificar, dominar e compreender as partes que compõem a sua estrutura, as quais possivelmente apresentam restrições

Cadernos do IL. Porto Alegre, n. ${ }^{o}$ 38, junho de 2009. p. 108-129. http://www.seer.ufrgs.br/cadernosdoil/ 
quanto a vários aspectos, o que justifica a preocupação do autor em formular uma proposta de operacionalização retórica da introdução de artigos científicos.

\section{A SESSÃO INTRODUTÓRIA DO GÊNERO ACADÊMICO ARTIGO CIENTÍFICO}

O artigo científico é de extrema importância para a disseminação do conhecimento construído em meio acadêmico (SWALES, 1990). Trata-se de texto escrito que retrata algum estudo científico realizado pelo autor e relacionado a outros estudos e/ou descobertas realizadas anteriormente, sendo publicável em revistas científicas específicas àquela área de estudo.

Brait (1996 apud MOTTA-ROTH, s.d.) compara a cultura de publicação na comunidade acadêmica à cultura do diálogo. Em vários momentos, não há simetria $\mathrm{e}$ harmoniosidade, pois se trata de resultados da interação de diferentes discursos por parte dos envolvidos em uma comunidade, cultura ou sociedade, bem como das convenções acadêmicas e da disciplina específica.

As publicações configuram-se como práticas sociais que têm como objetivo circular, expandir e (re)construir conhecimento dentro de uma comunidade discursiva, conforme apontam Figueiredo e Bonini (2005). Essas publicações são necessariamente veiculadas por meio do gênero artigo científico que apresenta restrições com relação a seu objetivo, posicionamento, convenções e valores formais e funcionais, o que justificaria o ensino de traços linguísticos, estruturais e retóricos desses gêneros.

O gênero em questão é composto por várias seções e, dentre elas, destacamos a introdução, bem como o título desses artigos, os quais, segundo Duszak (1995), devem encorajar e motivar o leitor a ler o artigo na íntegra, o que requereria uma atenção especial em sua produção por parte do autor a fim de motivar e "seduzir" o leitor a prosseguir a leitura.

De acordo com Aranha (2007), a introdução tem com propósito comunicativo introduzir o assunto a ser abordado ao longo do artigo, justificar a elaboração do estudo, bem como os procedimentos adotados. Torna-se, portanto, parte essencial em qualquer artigo de pesquisa, independentemente da área do conhecimento, e sua realização caracteriza-se como uma tarefa difícil tanto para falantes nativos como para não nativos (SWALES; FEAK, 1994). Talvez isso justifique a quantidade de trabalhos sobre gênero voltados para o estudo da introdução, como os de Swales (1990), que, apesar de abordar todas as seções de artigos de pesquisa, direciona maior atenção à introdução com o objetivo de tentar solucionar o problema da dificuldade encontrada pelos escritores na sua elaboração.

Aranha (1996), que também corrobora os estudos sobre a retórica das introduções, faz menção à enorme gama de opções que tem o escritor e sua responsabilidade em proceder suas escolhas (SWALES, 1990, p. 137 apud ARANHA, 1996), às dificuldades dos escritores em estabelecer os propósitos da introdução (GUPTA, 1995, p. 59 apud ARANHA, 1996), aos vários níveis referentes ao rigor do 
processo de composição que podem compor a organização interna da sessão introdutória (DUSZAK, 1995 apud ARANHA, 1996) e ainda à questão da interdependência entre o produto e o contexto de produção (BHATIA, 1993 apud ARANHA, 1996).

Para tentar auxiliar na resolução dessas e outras dificuldades relacionadas à produção de introduções, Swales (1990) propõe um modelo que apresenta as diferentes partes argumentativas que compõem a introdução, as quais denomina de moves (movimentos) que para Santos (1996, p. 27 apud ARANHA, 1996) são "blocos discursivos obrigatórios, organizados a partir da função retórica a ser desempenhada".

Esses movimentos são realizados a partir de steps (passos) que, segundo Aranha (2007, p. 105), são opcionais e "considerados estratégias retóricas, marcadas lexicalmente, sintaticamente, semanticamente e pragmaticamente". A combinação de movimentos e passos compõe a estrutura genérica da introdução que se configura no seguinte modelo de 1987:

Movimento 1: Estabelecendo o campo.

a) Mostrando centralidade.

b) Estabelecendo conhecimento.

c) Dando característica chaves.

Movimento 2: Resumindo pesquisa prévia.

a) Forte orientação para o autor.

b) Fraca orientação para o autor.

c) Orientação para o assunto.

Movimento 3: Preparando para a presente pesquisa.

a) Indicando uma brecha.

b) Levantando questões.

c) Estendendo um achado.

Movimento 4: Introduzindo a pesquisa.

a) Dando os objetivos.

b) Descrevendo a presente pesquisa.

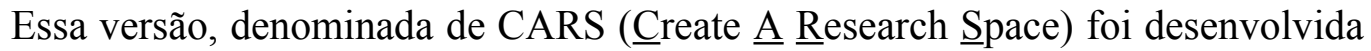
com base nos resultados de análise, primeiramente de 48 introduções de artigos de pesquisa e, posteriormente, de 110 introduções de três áreas diferentes: física, educação e psicologia e os resultados apontaram regularidades de quatro movimentos, conforme mostra o quadro anterior (HEMAIS; BIASI-RODRIGUES, 2005).

Em 1990, Swales, com base nas críticas que o modelo sofreu, reformula e apresenta-o no seguinte formato:

Cadernos do IL. Porto Alegre, n. ${ }^{\text {o } 38, ~ j u n h o ~ d e ~ 2009 . ~ p . ~ 108-129 . ~}$ http://www.seer.ufrgs.br/cadernosdoil/ 
Movimento 1 Estabelecendo um território.

Passo 1 Reivindicando centralidade e/ou

Passo 2: Tecendo generalização(ões) sobre o tópico e/ou

Passo 3: Revendo pontos de pesquisas anteriores.

Movimento 2 Estabelecendo um nicho.

Passo 1A: Apresentando alegações em contrário ou

Passo 1B: Indicando uma brecha ou

Passo 1C: Levantando questões ou

Passo 1D: Continuando a tradição.

Movimento 3 Ocupando o nicho

Passo 1A: Esboçando os objetivos ou

Passo 1B: Anunciando a presente pesquisa.

Passo 2: Anunciando os achados principais.

Passo 3: Indicando a estrutura do artigos de pesquisa (AP).

Esse modelo de operacionalização do gênero, conforme apontam Aranha (1996) e Hemais e Baisi-Rodrigues (2005), diferentemente do anterior, faz uma analogia ao sistema ecológico, porque considera o ambiente (contexto) no qual a pesquisa se insere e faz uso do termo nicho. Diferentemente do modelo anterior, este apresenta apenas três movimentos: Estabelecendo um território (M-1), Estabelecendo um nicho (M-2) e Ocupando o nicho (M-3).

Nesta segunda versão, os autores também atentam para o acréscimo de passos em cada um dos movimentos, ressaltam a importância dada à ocupação do nicho (M-3), em que o autor expõe o(s) objetivos(s) de sua pesquisa, bem como suas principais características e ainda apontam a modificação do status da função Rever itens de pesquisa prévia que antes ocupava a função de movimento e, a partir dessa nova proposta, passa a desempenhar a função de passo, tornando-se, assim, opcional e não mais obrigatório.

Hemais e Biasi-Rodrigues (2005, p. 122) apontam algumas pesquisas realizadas no Brasil que demonstram a aplicabilidade do modelo em diferentes gêneros, mas, apesar da relevância do modelo e dos vários estudos que apontam para sua viabilidade, alguns até mesmo em português, concordamos com o posicionamento de Aranha (2007) que indica alguns aspectos passíveis de crítica. Para a autora, um dos aspectos que deve ser ressaltado é a similaridade entre os passos Levantando questões (P1C) e Apresentando alegações ao contrário (P1A), o que conduz a uma possível simplificação, conforme proposto por Swales e Feak (1994, p. 175), ${ }^{2}$ tornando-o mais conciso e coerente em termos pedagógicos.

Aranha (1996) aplicou o modelo CARS (1990) em introduções científicas e reformulou alguns pontos que julgou pertinentes a partir dos resultados obtidos em seu estudo. A autora ressaltou a importância da citação de outros trabalhos na seção

${ }^{2}$ Cf. modelo em Swales e Feak (1994, p. 175).

Cadernos do IL. Porto Alegre, n. ${ }^{\text {o } 38, ~ j u n h o ~ d e ~ 2009 . ~ p . ~ 108-129 . ~}$ http://www.seer.ufrgs.br/cadernosdoil/ 
introdutória, elevando este passo ao status de movimento, uma vez que as referências a estudos realizados anteriormente relacionam o território e o nicho de pesquisa, mostram os pontos falhos da pesquisa e/ou fazem com que o leitor perceba a necessidade de mais estudos, além de relatarem os trabalhos que serviriam como ponto de partida para o pesquisador.

De acordo com Aranha, a exemplificação e/ou esclarecimento de pontos ou itens deve tornar-se um possível passo (P-3) ao se estabelecer território, bem como a sugestão para pesquisas posteriores ( $\mathrm{p}-5)$ ao ocupar o Nicho de pesquisa e sugere, de acordo com os resultados obtidos em sua pesquisa, que os passos possam ser vistos como opcionais, sem exceções.

A proposta modificada por Aranha (1996) para a operacionalização do gênero introdução se configura da seguinte forma:

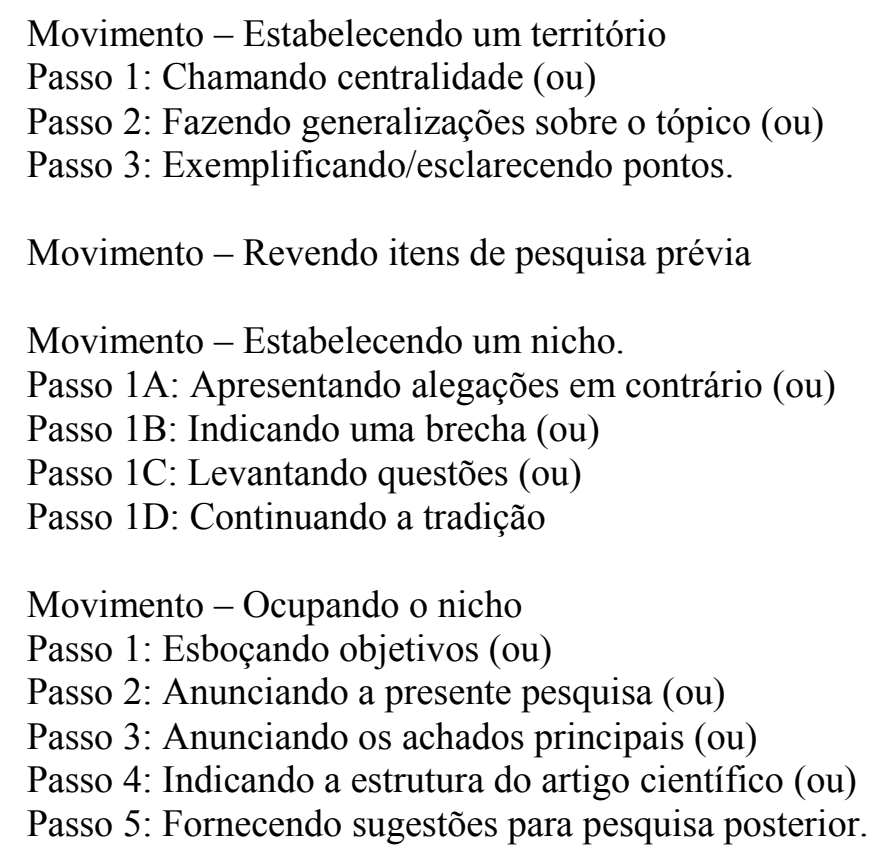

No que diz respeito às realizações linguísticas possíveis e/ou esperadas apresentados na construção dos passos sugeridos em cada movimento, Swales (1990) e Swales e Feak (1994) listam um rol de exemplos, relacionados ao movimento Estabelecendo um território (M-1), de acordo com a recorrência apontada em textos já analisados em língua inglesa, conforme podemos observar a seguir.

- Recently, there has been growing interesting in...

- Recently, researches have been increasingly interest in...

Cadernos do IL. Porto Alegre, n. ${ }^{\text {o } 38, ~ j u n h o ~ d e ~ 2009 . ~ p . ~ 108-129 . ~}$ http://www.seer.ufrgs.br/cadernosdoil/ 
- The possibility of... has generated wide interest in...

- The well-know...phenomena ... have been favorite topics for analysis in...

- Knowledge of...has a great importance for...

- The theory that ... has led to the hope that...

- A central issue in...is...

- X is well-know much evidence to support the hypothesis that...

- The ...properties of... are still not completely understood.

- A standard procedure for assessing has been ...

- Education core courses are often criticized for...

-...is a common finding in patients with...

- An elaborate system of... is found in the...

Com relação à revisão bibliográfica, a que Aranha (1996) dá o status de movimento, Swales (1990) acredita que pode ser feita de duas formas: integral e não integral. No primeiro caso, o nome do pesquisador é parte do elemento da oração e, no segundo, é mencionado entre parênteses ou em outro lugar, de acordo com a área de pesquisa.

Ao estabelecer um nicho, os autores situam sua pesquisa dentro do âmbito mais amplo relatado ao estabelecer um território, e, conforme indicado no modelo de revisto por Aranha (1996), ele pode ser realizado por meio de alegações ao contrário, indicação de uma brecha, levantamento de questões ou simplesmente por meio da continuação da tradição.

As ocorrências linguísticas recorrentes nos resultados de pesquisa apresentados por Swales (1990) ao estabelecer um nicho são: a) quantificadores negativos (no, little, none...); b) negação léxica realizada por meio de verbos (fail, lack, suffer from...), de adjetivos (inconclusive, complex, scarse...) e de substantivos (failure, limitation...); c) negação no sintagma verbal (not, ill...); d) levantamento de problemas, e) conclusões lógicas (must, seem/appear, expect); f) desejos/interesses e necessidades expressas; g) interrogações e, por fim, h) comentários constrativos.

As brechas ou falhas da pesquisa (P-1B) são apresentadas por meio de verbos e adjetivos, que serão listados a seguir de acordo com Swales e Feak (1994, p.187 apud ARANHA, 2007, p. 111):

Verbos: Ex: However, previous research in this Field has

1. concentrated on $\mathrm{x}$

2. disregarded $\mathrm{x}$

3. failed to consider $\mathrm{x}$

4. ignored $\mathrm{x}$

5. been limited to $\mathrm{x}$

6. misinterpreted $\mathrm{x}$

7. neglected to consider $\mathrm{x}$

8. overestimated $\mathrm{x}$

9. overlooked $\mathrm{x}$

Cadernos do IL. Porto Alegre, n. ${ }^{o}$ 38, junho de 2009. p. 108-129. http://www.seer.ufrgs.br/cadernosdoil/ 
10. been restricted to $\mathrm{x}$

11. suffered from $\mathrm{x}$

12. underestimated $\mathrm{x}$

Adjetivos: Ex: Nevertheless, these attempts to establish a link between secondary smoke and lung cancer are at present
1. controversial
2. incomplete
3. inconclusive
4. misguided
5. questionable
6. unconvincing
7. unsatisfactory

O movimento Ocupando nicho tem como objetivo justificar a pesquisa e normalmente é introduzido ou por this, the present, reported e here e/ou pela mudança da forma impessoal, utilizada até então pelo autor, para a forma pessoal (SWALES, 1990).

$\mathrm{Na}$ análise do presente artigo, nos basearemos nas evidências linguísticas apontadas anteriormente e aplicaremos o modelo de Aranha (1996), que se baseia em Swales (1990), porque concordamos com as alterações realizadas pela autora em relação aos modelos anteriores e acreditamos em sua viabilidade no âmbito pedagógico devido a sua simplicidade e coerência.

\section{METODOLOGIA}

\section{CARACTERÍSTICA DO CORPUS}

O corpus que compõe este trabalho é composto por 10 artigos científicos, sendo cinco deles publicados na revista Tecnologie Didattiche (doravante TD) do instituto de tecnologia didática de Gênova, que se dedica aos estudos das inovações educativas que estão associadas ao uso da tecnologia de informação e comunicação (TIC) na Itália. Cada número da revista apresenta uma temática específica e se direciona ao público de maneira geral (aos professores, aos formadores e aos estudos do departamento de ciências da educação, entre outros) que se interessa pelas inovações nos sistema de ensino e aprendizagem. Todos os artigos propostos são avaliados pelos especialistas da área. É uma revista quadrimestral, a primeira edição foi publicada em 1993. Utilizamos os artigos que estão disponíveis on-line.

Os outros cinco artigos foram publicados na Rivista Italiana di Ornitologia (doravante RO), que tem como principal responsável o professor Cesare Conci do Museo Cívico di Storia Naturale di Milano. A revista publica artigos e notas preferencialmente em língua italiana ou inglesa. Para receber a revista italiana é

Cadernos do IL. Porto Alegre, n. ${ }^{\text {o } 38, ~ j u n h o ~ d e ~ 2009 . ~ p . ~ 108-129 . ~}$ http://www.seer.ufrgs.br/cadernosdoil/ 
necessário ser associado a sociedade italiana de Ciências Naturais (Società Italiana di Scienze Naturali (SINS)). Nosso acesso à revista foi realizado por meio de consultas à biblioteca de uma universidade pública.

Convém atentarmos para uma característica desse corpus que foge à tendência das introduções com relação a sua autoria, apontado por Swales (2004, p. 216). O autor, baseado na incidência verificada em outros textos, relata que grande parte dos artigos é escrita por dois ou mais autores, já no caso deste estudo somente $30 \%$ dos artigos analisados foram escritos por dois autores.

Seguem abaixo os artigos de cada revista que foram numerados para facilitar a retomada destes artigos ao longo deste estudo.

Tabela 1 - Data de publicação das revistas

\begin{tabular}{|c|c|c|c|}
\hline Número & Ano de publicação & Número & Ano de publicação \\
\hline 01 & 2005 & 01 & $2006^{\mathbf{a}}$ \\
\hline 02 & $2006^{\mathbf{a}}$ & 02 & $2006 \mathrm{~b}$ \\
\hline 03 & 2005 & 03 & 2004 \\
\hline 04 & $2006 \mathrm{~b}$ & 04 & 2004 \\
\hline 05 & 2005 & 05 & 2000 \\
\hline
\end{tabular}

\section{CRITÉRIOS PARA A SELEÇÃO DAS REVISTAS E COLETA DOS DADOS}

As revistas italianas não são classificadas a partir de critérios como os disponíveis no site da CAPES (Coordenação de Aperfeiçoamento de Pessoal de Nível Superior) para revistas brasileiras. Assim sendo, procuramos selecionar revistas conceituadas em duas áreas de conhecimentos distintas e, para isso, pautamo-nos na indicação de uma professora nativa italiana, doutoranda da área de tecnologia, bem como nas visitas à biblioteca da universidade e acesso a sites para recolhermos informações sobre as revistas (diretores, publicação, público-alvo, etc).

Após selecionarmos as revistas, o segundo critério foi a escolha de exemplares que estivessem disponíveis na biblioteca, no caso da Revista de Ornitologia (doravante RO) e on-line, no caso da Tecnologie Didattiche (doravante TD). Em seguida, o critério foi referente à nacionalidade dos autores, a fim de colaborarmos com uma padronização no que se refere às evidências linguísticas e estruturas argumentativas utilizadas por falantes nativos da língua em questão.

Cadernos do IL. Porto Alegre, n. ${ }^{\circ} 38$, junho de 2009. p. 108-129. 


\section{FORMA DE ANÁLISE}

Para análise dos dez artigos de pesquisas selecionados, conforme relatamos anteriormente, aplicamos o modelo CARS de operacionalização, proposto por Aranha (1996), atentando para sua viabilidade em artigos de língua italiana como também para a diferença e/ou semelhança entre ambos, uma vez que se trata de duas áreas de conhecimento distintas, que estão intrinsecamente relacionadas à organização social e à atividade de cada área.

\section{ANÁLISE E DISCUSSÃO DOS DADOS}

Esta seção tem como objetivo a análise e discussão da estrutura genérica das introduções bem como de suas realizações linguísticas. Iniciamos a análise apresentando as evidências comuns a todos os artigos analisados. A revisão dos itens de pesquisa, por exemplo, se faz presente em todas as introduções analisadas, o que denota sua importância, corroborando e justificando a necessidade de alçar este passo para o status de movimento, conforme propõem Swales e Feak (1994) e Aranha (1996) ao revisar o modelo CARS.

Além disso, a revisão presente em todos os artigos é feita por meio de referências bibliográficas ao longo das introduções de maneira não integral, uma vez que o nome do teórico/pesquisador não aparece integrado ao corpo do texto, mas sim separado por parênteses e por colchetes, como nos exemplos que segue, extraídos respectivamente da revista $\mathrm{RO}$ e a TD.

Delle sette specie di Aironi coloniali del nostro paese, due sono di recente colonizzazione: Airone guardabuoi, Bubulcus ibis (GRUSSU \& SECCI, 1986) e Airone bianco maggiore, Egretta alba, (AMATO et alli, 1995; VOLPONI \& EMILIANI, 1995); due, Nitticora, Nycticorax nycticorax, e Garzetta, Egretta garzetta, sono presenti con le popolazioni più consistenti del continente europeo, rispettivamente, circa il $40 \%$ e circa il $30 \%$ dele popolazioni contientale (FASOLA et alli, 1981; FASOLA, 1983). (RO, n.0 $4)^{3}$

Sul piano didattico è evidente come il ruolo docente, pur mantenendo la sua centralità, venga a modificarsi,; quanto si modifichi dipende ovviamente dal tipo di approccio adottato, e cioè se parzialmente o totalmente basato sull'uso delle ICT [Laurillard, 1993] [Fuller e Norby, 2000] [Young, 2002]. (TD, n. 01$)^{4}$

\footnotetext{
${ }^{3}$ Das sete espécies de Garça colonial do nosso país, duas são de recente colonização: Garça-vaqueira, Buculcus íbis (GRUSSU \& SECCI, 1986) e Garça branca maior, Egretta alba, (AMATO et alli, 1995; VOLPONI \& EMILIANI, 1995); duas, Nitticora, Nycticorax nycticorax, e Garzetta, Egretta garzetta, estão presentes com as populações mais consistentes do continente europeo, respectivamente, cerca de $40 \%$ e cerca de $30 \%$ da população continental (FASOLA et alli, 1981; FASOLA, 1983) (tradução nossa). ${ }^{4}$ A nível didático, é evidente como o papel docente, ainda que mantendo a centralidade, venha a modificar-se; o quanto é modificado depende obviamente do tipo de abordagem adotado, ou seja, se é
}

Cadernos do IL. Porto Alegre, n. ${ }^{o}$ 38, junho de 2009. p. 108-129. http://www.seer.ufrgs.br/cadernosdoil/ 
A forma como este movimento é apresentado corrobora os resultados de análise da pesquisa de Cai (2008) e as considerações de Swales (2004) sobre a falta de personalização das citações de trabalhos alheios quando estas são apresentadas de maneira não integrada, como revelam as introduções analisadas neste trabalho.

Na revista TD, os autores, juntamente com as respectivas datas de publicação de seu trabalho são separados por colchetes, exemplo: [Fuller e Norby, 2002]; encontramos essa forma de citação nos cinco artigos analisados. Já na revista RO, a citação é feita de maneira convencional, usando os parênteses, exemplo (Cambi \& Niederfriniger in BRICHETTI, 1983; BRICHETTI, 1987).

É importante ressaltar também a recorrência desse movimento. Nos artigos da RO, esse movimento aparece mais de uma vez, no mínimo duas e, conforme apontam Aranha (1996) e Swales e Feak (1994), torna-se difícil indissociar o passo 2 - Fazendo generalizações sobre o tópico (optativo) do movimento Revendo itens de pesquisa prévia, pois ambos estão intrinsecamente relacionados.

Os cinco artigos analisados apresentam o passo Chamando centralidade (P-1) do movimento Estabelecendo um território e, e em todos os casos, os autores fazem citações de trabalhos já realizados (Revendo itens de pesquisa prévia-M) para validarem ainda mais a importância do estudo em questão, como no exemplo a seguir, em que o autor utiliza-se de seis citações para auxiliá-lo na comprovação de que a pesquisa sobre ornitocenosi urbane está se expandindo cada vez mais.

La ricerca scientifica sulle ornitocenosi urbane non ha riguardato, ovviamente, solo I'Italia; essa è andata sviluppandosi anche nel resto del mondo, con numerose ricerche sia di tipo faunistico che ecologico, spesso raccolte in atti di convegni e monografie (FRAISSINET, 1992/93; ADAMS, 1994; BIRD et al., 1996; CACCAMISE \& LUNIAK, 1996; FRAISSINET et al, 1996; BOLOGNA, CARPANETO \& CIGNINI, 1998). (RO, n.05)

Ao reivindicar centralidade os autores fazem uso de algumas ocorrências linguísticas: più studiati (n.01), oggetti di numerosi studi (n.02), maggiore interesse per il fenomeno (n.03), un buon modello di studio per censimenti (n.04). Já no artigo 05, essa centralidade é realizada quando o autor argumenta sobre a necessidade de formação de um grupo de pesquisa científica:

Nel corso del decennio'90 lo studio dell'avifauna urbana è andato ulteriormente evolvendosi, al punto da comportare, per L'Italia, l'esigenza di costituire uno specifico Gruppo scientifico sull'Avifauna urbana (DINETTI et al, 1995; DINETTI \& FRAISSINET, 1998). (RO, n.05) ${ }^{6}$

parcialmente ou totalmente baseado sobre o uso das TIC [Laurillard, 1993] [Fuller e Norby, 2000] [Young, 2002].

${ }^{5}$ A pesquisa científica sobre ornitocenoses urbanas não foi realizada, obviamente, apenas na Itália; ela foi desenvolvida também no resto do mundo, com numerosas pesquisas tanto de tipo faunístico quanto ecológico, encontradas frequentemente em atas de congressos e monografias (FRAISSINET, 1992/93; ADAMS, 1994; BIRD et al., 1996; CACCAMISE \& LUNIAK, 1996; FRAISSINET et al, 1996; BOLOGNA, CARPANETO \& CIGNINI, 1998) (tradução nossa).

Cadernos do IL. Porto Alegre, n. ${ }^{o}$ 38, junho de 2009. p. 108-129. http://www.seer.ufrgs.br/cadernosdoil/ 
É importante atentar que, diferentemente da estrutura dos outros quatro artigos, este se iniciou chamando centralidade para o tema pesquisado pelo autor.

Já com relação à revista $\mathrm{TD}$, três dos cinco artigos contêm esse passo, que é manifestado por meio do sintagma grande attenzione, elemento cruciale (n.05), e das construções: oggetto di studio sempre più diffuso (n.03) e ...ha solleciato l'urgenza di uma riflessione approfondità sull'argomento e ainda La narrativa sta ora emergendo come oggetto di studio di ricerca... (n.04). ${ }^{7}$

Ainda no que se refere ao movimento Estabelecendo um território, notamos que o autor do artigo 01 da revista $\mathrm{RO}$, ao fazer generalizações sobre o tópico (P-2), utiliza a locução advérbial de afirmação "con certezza" que implica um comprometimento do autor com o que é dito, mas que é amenizado logo em seguida pela citação de autores da área, que comprovam o embasamento teórico da afirmação, conforme podemos observar no excerto que segue.

Sull' Elba la Pernice rossa è segnalata con certezza dal 1808 (THIÉBAUT DE BERNEAUD,1993) (grifo nosso). ${ }^{8}$

Essa construção corrobora com as afirmações de Aranha (1996) que considera esse passo neutro, no qual o autor não estabelece um comprometimento com o assunto em questão, uma vez que todas as afirmações são embasadas teórica e cientificamente.

Quanto ao passo opcional Exemplificando/esclarecendo pontos (P-3), pudemos observar que está presente apenas nas introduções da revista TD, talvez porque as introduções sejam mais extensas e o assunto por ser novo e atual requer maiores esclarecimentos. Esse passo se faz presente em três das cinco introduções, apresentando uma recorrência considerável de três vezes em um mesmo artigo.

A seguir, segue um exemplo em que o autor utiliza inclusive símbolos para marcar os itens apontados:

Si tratta di un approccio che ha bisogno di diverse condizioni al contorno per poter essere attuato con un certa efficacia (di qui il suo limitato utilizzo), quali ad esempio [Harasim, 1990] [Barron, 2000] [Felder e Brent, 2001] [Palloff e Pratt, 2002]:

- la disponibilità del docente a ridisegnare il corso, modificandolo anche consistentemente rispetto alla versione pensata per una didattica in presenza;

-una preparazione specifica dei docenti (e degli eventuali tutor) riguardo sia la progettazione di attività didattiche basate sull'aprendimento in rete sia le modalità di organizzazione e gestione di gruppi di studio online;

\footnotetext{
${ }^{6}$ No decorrer da década de 1990, o estudo da avifauna urbana foi se desenvolvendo de modo subsequente a ponto de implicar, pela Itália, à exigência da constituição de um específico grupo científico sobre a avifauna urbana (DINETTI et al, 1995; DINETTI \& FRAISSINET, 1998) (tradução nossa).

${ }^{7}$ objeto de estudo sempre mais difundido (n.03) e ...tem requerido urgência de uma reflexão profunda sobre o assunto e ainda A narrativa está emergindo, no momento, como objeto de estudo de pesquisa... (tradução nossa).

${ }^{8}$ Na Elba a Perdiz Vermelha foi notada com certeza desde 1808 (THIÉBAUT DE BERNEAUD, 1993) (tradução e grifos nossos).
}

Cadernos do IL. Porto Alegre, n. ${ }^{\text {o } 38, ~ j u n h o ~ d e ~ 2009 . ~ p . ~ 108-129 . ~}$ http://www.seer.ufrgs.br/cadernosdoil/ 
- la pertinenza della strategia collaborativa rispetto agli obiettivi formativi dichiarati per il corso o per parte di esso

- la presenza di classi numericamente limitate in cui si possa garantire un rapporto di 1/15 -1/20 fra docente (e/o tutor) e studenti;

- la disponibilità di adeguati servizi di rete per la comunicazione di gruppo entro cui allestire e struturare lo spazio virtuale in grado di ospitare le interazioni a distanza fra tutti gli attori del processo (studenti, docenti, tutor, ecc.), definendo al contempo le regole sia di gestione sia di uso da parte degli studenti; $[\ldots](\mathrm{TD}, \mathrm{n} .01)^{9}$

- la possibilità per gli studenti di accedere frequentemente alla rete.

É importante observar que neste mesmo artigo do qual extraímos o excerto anterior, o autor, ao fazer a revisão bibliográfica, cita o termo apprendimento in rete e faz uso de nota de rodapé para explicar o seu significado embasado cientificamente. $\mathrm{O}$ autor faz, portanto, uma referência bibliográfica no formato de nota de rodapé, diferentemente das outras introduções aqui analisadas.

1. Il termine apprendimento in rete qui non sta solo a significare che nel processo formativo si faccia uso di uma rete di computer, quanto piuttosto che ci si basi su una rete di interrelazioni funzionali alle attività di una comunità cooperante nel raggiungimento di uno specifico obiettivo educativo. La rete, quindi, vista prima di tutto come rete sociale di individui, ancorchérete telematica necessaria alla comunicazione a distanza fra quegli stessi individui. [Trentin, 2001] (TD, n.01). ${ }^{10}$

Outros dois artigos, além do citado acima, também trazem notas de rodapé. Em um deles (TD, n.02), para fornecer maiores informações sobre o projeto mencionado. É

\footnotetext{
${ }^{9}$ Se trata de uma abordagem que necessita de muitas condições ao redor para poder atuar com uma certa eficácia (por este motivo a sua utilização limitada), por exemplo [Harasim, 1990] [Barron, 2000] [Felder e Brent, 2001] [Palloff e Pratt, 2002]:

- A disponibilidade do docente para redesenhar o corso, modificando-o também consistentemente em relação à versão planejada para uma didática presencial;

- Uma preparação específica dos docentes (e dos eventuais tutores) com relação tanto à projeção de atividades didáticas baseadas na aprendizagem em rede quanto às modalidades de organização e gestão de grupos de estudos online;

- A pertinência da estratégia colaborativa a respeito dos objetivos formativos declarados para o curso ou parte dele;

- A presença de classes numericamente limitadas nas quais se possa garantir uma relação de $1 / 15-1 / 20$ entre docente (e/ou tutor) e estudantes;

- A disponibilidade de adequados serviços de rede para a comunicação de grupo dentro dos quais preparar e estruturar o espaço virtual capaz de hospedar as interações a distância entre todos os atores do processo (estudantes, docentes, tutor, etc), definindo ao mesmo tempo as regras seja de gestão, seja do uso por parte dos estudantes

- A possibilidade para os estudantes de acessar frequentemente a rede (tradução nossa).

${ }^{10} \mathrm{O}$ termo aprendizagem em rede aqui não está apenas significando que no processo formativo se faça uso de uma rede de computadores, mas também que se baseie sobre uma rede de inter-relações funcionais às atividades de uma comunidade cooperante em alcançar um específico objetivo educativo. A rede, então, vista antes de tudo como uma rede social de indivíduos, ainda que seja rede telemática necessária à comunicação a distância entre aqueles mesmos indivíduos (tradução nossa).
}

Cadernos do IL. Porto Alegre, n. ${ }^{\text {o } 38, ~ j u n h o ~ d e ~ 2009 . ~ p . ~ 108-129 . ~}$ http://www.seer.ufrgs.br/cadernosdoil/ 
interessante observar que o autor utiliza a língua inglesa para fazer essa nota, e no artigo 03 para citarem a fonte (referência bibliográfica), o que não ocorreu nos artigos da revista RO. A seguir mostramos respectivamente as notas de rodapé mencionadas.

1. Self-regulated Learning in Technology Enhanced Learning Environments at University Level: a Peer Review", Grant agreement 2003-4710-/001-001 EDU-ELEARN, http://www.Imi.ub.es/telepeers/. (TD, n.02)

1. Cf. Midoro V. (ed) (2005), A Commom European Framework for Teachers' professional profile in ICT for Education, Menabò, Ortona. (TD, n.03)

Além desse fato, observamos uma outra característica típica das introduções da revista TD. Embora muito mais extensas do que a $\mathrm{RO}$, não trazem na revisão bibliográfica um grande número de teóricos como, por exemplo, a introdução do artigo 03, em que a revisão é realizada com base em um único autor.

No que concerne ao movimento Estabelecendo um nicho, constatamos que este se faz presente em cada uma das introduções de cada artigo analisado e que traz um dos três passos sugeridos no modelo CARS. Dentre as dez introduções, cinco delas estabelecem o nicho por meio do passo $1 \mathrm{D}$ - Continuando a tradição.

$\mathrm{O}$ artigo n.02 da revista TD apresenta o passo $1 \mathrm{C}$ - Levantando questões, uma vez que propõe duas questões, baseadas em trabalhos anteriores, características desse passo, conforme aponta Aranha (1996), e que estão também relacionadas aos objetivos a serem atingidos por meio do desenvolvimento do trabalho em questão.

Per chi si occupa di didattica e di tecnologie didattiche è quindi necessario chierdersi: è possibile realizzare ambienti tecnologici (dove per ambiente intendiamo non solo lo strumento software ma anche la sua metodologia d'uso) che abbiano la potenzialità di incoraggiare gli studenti all' autoregolazone ed aiurtali a sviluppare questa competenza? Come valutare il supporto fornito all'autoregolazione da un ambiente di apprendimento? (TD, n.02 $)^{11}$

No artigo 05, o autor indica uma brecha ao afirmar que se trata de um aspecto pouco estudado: ...un aspetto ancora poco studiato (TD, n.05, grifo nosso). É interessante observar a negação no sintagma verbal, em destaque na frase realizado por meio dos advérbios ancora e poco, que revela a lacuna de pesquisa.

Com relação às duas introduções da RO, em uma delas (artigo n.02) o autor, ao reivindicar centralidade, apoia-se em outros autores e usa o vocábulo priorità di conservazione e, em seguida, mostra que a espécie não tem sido objeto de estudos

\footnotetext{
${ }^{11}$ Para quem se ocupa de didática e de tecnologias didáticas faz-se necessário perguntar-se: é possível realizar ambientes tecnológicos (onde por ambiente entendemos não apenas o instrumento software, mas também a sua metodologia de uso) que tenham a potencialidade de encorajar os estudantes à autoregulação e ajudá-los a desenvolver esta competência? Como avaliar o suporte fornecido à autoregulação por um ambiente de aprendizagem?
}

Cadernos do IL. Porto Alegre, n. ${ }^{\text {o } 38, ~ j u n h o ~ d e ~ 2009 . ~ p . ~ 108-129 . ~}$ http://www.seer.ufrgs.br/cadernosdoil/ 
específicos. Para tanto, não necessariamente utiliza uma conjunção adversativa para estabelecer a ligação:

Inserita nelle liste rosse regionali degli uccelli nidificanti e considerata a priorità di conservazione (SPOSIMO \&TELLINI, 1995; FORNASARI, 2003), la specie non è fatta oggetto di studi specifici. (RO, n.02) ${ }^{12}$

Assim sendo, ele não insere o passo Indicando uma brecha (1-B) por meio de conjunções, conforme são apontados nas possibilidades levantadas por Swales (1990), mas utiliza somente o advérbio no sintagma verbal de negação: non è stata fatta oggetto di studi specifici.

Já com relação ao artigo 01, há uma sinalização de que seu trabalho será uma continuação daquilo que já vem sendo pesquisado, pois o autor revê os pontos de sua própria pesquisa para continuar a tradição, ou seja, o que tem sido realizado cientificamente, e esboça concomitantemente o objetivo de apresentar a sua pesquisa de maneira mais aprofundada e extensiva.

\begin{abstract}
Considerando che i risultati di quell' ultima indagine furono presentati alla comunità scientifica solo in maniera molto sintetica (GARIBOLDI, 1997) e che recentemente, grazie anche alla presenza del Parco Nazionale dell'Arcipelago Toscano, sono riprese le ricerche sulla specie all'Elba (PUGLISI, com. pers.), si è ritenuto utile presentare in maniera più approfondita ed estensiva quella ricerca. (RO, n.01, grifos nossos) $)^{13}$
\end{abstract}

No que diz respeito à Ocupação do Nicho, Aranha (1996) acredita que seu objetivo principal seria o de justificar o artigo científico e especificar seus propósitos. Dessa forma, toda a introdução necessitaria apresentar o passo Esboçando os objetivos ou Anunciando a presente pesquisa, que é marcado pelo uso de referências dêiticas, a partir de uma estrutura que indica que ou autor optou por um sujeito inanimado ao omitir o animado.

Com relação à revista $\mathrm{TD}$, as marcas do sujeito inanimado são: In questo articolo... (artigos 01 e 03) e Questo contributo introduce... (n.02). Nos artigos 04 e 05, há uma mudança de pessoa: o autor deixa de usar a forma impessoal para usar a terceira pessoa do plural: ci proponiamo... (n.05) e In questo lavoro caratterizziamo... (n.04).

Já na revista RO, prevalece o uso da forma impessoal (artigos 01, 03, 04 e 05): ...si è ritenuto utile presentare in maniera più approfondita... (n.01), ...oggetto di questa

\footnotetext{
${ }^{12}$ Inserida nas listas vermelhas regionais dos pássaros nidificantes e considerada como prioridade de conservação (SPOSIMO \& TELLINI, 1995; FORNASARI, 2003), a espécie não é feita objeto de estudos específicos.

${ }^{13}$ Considerando que os resultados daquela última pesquisa foram apresentados à comunidade científica apenas de maneira muito sintética (GARIBOLDI, 1997) e que, recentemente, graças também à presença do Parque Nacional do Arquipélago Toscano, foram retomadas as pesquisas sobre a espécie na Elba (PUGLISI, com. pers.), foi considerado útil apresentar de maneira mais aprofundada e extensiva aquela pesquisa.
}

Cadernos do IL. Porto Alegre, n. ${ }^{\circ} 38$, junho de 2009. p. 108-129. 
nota è la descrizione... (n.03), In questo lavoro è voluto indagare... (n.04), Con questo lavoro si è provato... (n.05). ${ }^{14}$

Diferentemente do que ocorre nessas quatro introduções, na de número 02 não é utilizado a forma impessoal para esboçar os objetivos ou anunciar a pesquisa. Por meio de um elemento dêitico que se refere ao tipo de pesquisa (no caso lavoro), o autor introduz, usando o verbo no tempo presente, o objetivo de sua pesquisa. É importante observar que o autor muda da forma impessoal apresentada até então para a forma pessoal (primeira pessoa), marcada na terminação do verbo riportiamo.

Nel lavoro riportiamo e risultati di un' indagine pluriennale mirata all' approfondimento delle caratteristiche dell' Italia centrale. (RO, n. 02, grifo nosso $)^{15}$

Apresentamos abaixo um quadro resumitivo que contém os movimentos presentes em cada introdução científica. Como podemos observar os quatro movimentos Estabelecendo um território, Revendo itens de pesquisa prévia, Estabelecendo um nicho e Ocupando o nicho, estão presentes em todos os artigos, porém são realizados de maneira peculiar por meio dos passos e de suas estruturas linguísticas.

Tabela 2 - Movimentos e Passos da revista Tecnologie Didattiche (tudo)

\begin{tabular}{|c|c|c|c|c|}
\hline Número & Estabelecendo um território & $\begin{array}{l}\text { Revendo } \\
\text { itens de } \\
\text { pesquisa } \\
\text { prévia }\end{array}$ & $\begin{array}{l}\text { Estabelecendo } \\
\text { um nicho }\end{array}$ & Ocupando o nicho \\
\hline 01 & $\begin{array}{c}\text { Reivindicando } \\
\text { Centralidade } \\
\text { Exemplificando/esclarecendo pontos }\end{array}$ & $\mathrm{X}$ & $\begin{array}{l}\text { Continuando a } \\
\text { tradição }\end{array}$ & $\begin{array}{c}\text { Esboçando o objetivo } \\
\text { ou anunciando a } \\
\text { presente pesquisa }\end{array}$ \\
\hline 02 & $\begin{array}{c}\text { Reivindicando } \\
\text { Centralidade } \\
\text { Exemplificando/esclarecendo pontos }\end{array}$ & $X$ & $\begin{array}{l}\text { Levantando } \\
\text { questões }\end{array}$ & $\begin{array}{c}\text { Esboçando o objetivo } \\
\text { ou anunciando a } \\
\text { presente pesquisa }\end{array}$ \\
\hline 03 & $\begin{array}{c}\text { Reivindicando } \\
\text { Centralidade } \\
\text { Exemplificando/esclarecendo pontos }\end{array}$ & $\mathrm{X}$ & $\begin{array}{l}\text { Continuando a } \\
\text { tradição }\end{array}$ & $\begin{array}{c}\text { Esboçando o objetivo } \\
\text { ou anunciando a } \\
\text { presente pesquisa }\end{array}$ \\
\hline 04 & $\begin{array}{c}\text { Reivindicando } \\
\text { Centralidade }\end{array}$ & $X$ & $\begin{array}{l}\text { Continuando a } \\
\text { tradição }\end{array}$ & $\begin{array}{c}\text { Esboçando o objetivo } \\
\text { ou anunciando a } \\
\text { presente pesquisa }\end{array}$ \\
\hline 05 & $\begin{array}{l}\text { Reivindicando } \\
\text { Centralidade }\end{array}$ & $X$ & $\begin{array}{l}\text { Indicando uma } \\
\text { brecha }\end{array}$ & $\begin{array}{c}\text { Esboçando o objetivo } \\
\text { ou anunciando a } \\
\text { presente pesquisa }\end{array}$ \\
\hline
\end{tabular}

14 ...foi considerado útil apresentar de maneira mais profunda... (n.01), ...objeto desta nota é descrição... (03), Neste trabalho, quis-se indagar...(04), Com este trabalho provou-se...(n.05).

${ }^{15}$ No trabalho relatamos os resultados de uma pesquisa de vários anos objetivando o aprofundamento das características da Itália central.

Cadernos do IL. Porto Alegre, n. ${ }^{\text {o } 38, ~ j u n h o ~ d e ~ 2009 . ~ p . ~ 108-129 . ~}$ 
Cadernos do IL e Cadernos do IL e Cadernos do IL e Cadernos do IL e Cadernos do IL e Cadernos do IL

Tabela 3 - Movimentos e Passos da Rivista di Ornitologia (RO)

\begin{tabular}{|c|c|c|c|c|}
\hline Número & $\begin{array}{l}\text { Estabelecendo } \\
\text { um território }\end{array}$ & $\begin{array}{l}\text { Revendo itens de } \\
\text { pesquisa prévia }\end{array}$ & $\begin{array}{l}\text { Estabelecendo um } \\
\text { nicho }\end{array}$ & $\begin{array}{l}\text { Ocupando o } \\
\text { nicho }\end{array}$ \\
\hline 01 & $\begin{array}{c}\text { Reivindicando } \\
\text { Centralidade }\end{array}$ & X & $\begin{array}{l}\text { Continuando a } \\
\text { tradição de sua } \\
\text { própria pesquisa }\end{array}$ & $\begin{array}{c}\text { Esboçando o } \\
\text { objetivo ou } \\
\text { anunciando a } \\
\text { presente } \\
\text { pesquisa }\end{array}$ \\
\hline 02 & $\begin{array}{c}\text { Reivindicando } \\
\text { Centralidade }\end{array}$ & $\mathrm{X}$ & Indicando uma brecha & $\begin{array}{c}\text { Esboçando o } \\
\text { objetivo ou } \\
\text { anunciando a } \\
\text { presente } \\
\text { pesquisa }\end{array}$ \\
\hline 03 & $\begin{array}{c}\text { Reivindicando } \\
\text { Centralidade }\end{array}$ & $\mathrm{X}$ & $\begin{array}{l}\text { Continuando a } \\
\text { tradição }\end{array}$ & $\begin{array}{l}\text { Esboçando o } \\
\text { objetivo ou } \\
\text { anunciando a } \\
\text { presente } \\
\text { pesquisa }\end{array}$ \\
\hline 04 & $\begin{array}{c}\text { Reivindicando } \\
\text { Centralidade }\end{array}$ & $\mathrm{X}$ & $\begin{array}{l}\text { Continuando a } \\
\text { tradição }\end{array}$ & $\begin{array}{l}\text { Esboçando o } \\
\text { objetivo ou } \\
\text { anunciando a } \\
\text { presente } \\
\text { pesquisa }\end{array}$ \\
\hline 05 & $\begin{array}{c}\text { Reivindicando } \\
\text { Centralidade }\end{array}$ & $X$ & $\begin{array}{l}\text { Continuando a } \\
\text { tradição }\end{array}$ & $\begin{array}{c}\text { Esboçando o } \\
\text { objetivo ou } \\
\text { anunciando a } \\
\text { presente } \\
\text { pesquisa }\end{array}$ \\
\hline
\end{tabular}

A seguir, apresentamos os quadros com as evidências linguísticas apontas na análise dos artigos.

Cadernos do IL. Porto Alegre, n. ${ }^{\text {o } 38, ~ j u n h o ~ d e ~ 2009 . ~ p . ~ 108-129 . ~}$

http://www.seer.ufrgs.br/cadernosdoil/ 
Quadro 1 - Evidências Linguísticas

\begin{tabular}{|c|c|}
\hline \multicolumn{2}{|c|}{ Evidências Linguísticas } \\
\hline $\begin{array}{l}\text { RO } \\
\text { Più studiati } \\
\text { Oggetti di numerosi studi } \\
\text { Maggiore interesse per il fenomeno } \\
\text { Um buon modello di studio per censimenti } \\
\text { Prioritá } \\
\text { TD }\end{array}$ & $\begin{array}{l}\text { Centralidade (P-1) } \\
\text { TD } \\
\text { Grande attenzione } \\
\text { Elemento cruciale } \\
\text { Oggetto di studio più diffuso } \\
\text { Ha solleciato l'urgenza di una approfondità } \\
\text { sull'argomento. } \\
\text { La narrativa sta emergendo come oggetto di studio } \\
\text { di ricerca }\end{array}$ \\
\hline $\begin{array}{l}\text { Esboçando os objetivos (P-1) (ou) } \\
\text { Marcas do sujeito inanimado } \\
\text { TD } \\
\text { In questo articolo } \\
\text { Questo contributo introduce } \\
\text { Forma pessoal } \\
\text { Ci proponiamo } \\
\text { In questo lavoro caratterizziamo }\end{array}$ & $\begin{array}{l}\text { Anunciando a presente pesquisa (P-2) } \\
\text { Forma impessoal } \\
\text { RO } \\
\mathrm{Si} \mathrm{è} \mathrm{ritenuto} \mathrm{utile} \mathrm{presentare} \mathrm{in} \mathrm{maniera} \mathrm{più} \\
\text { approfondita oggeto di questa nota è ... } \\
\text { In questo lavoro } \\
\text { Forma pessoal } \\
\text { Riportiamo }\end{array}$ \\
\hline $\begin{array}{l}\text { Levantamento de uma brecha (P- 1C) } \\
\text { TO } \\
\text { Advérbios: ancora, poco. } \\
\text { Non è fatta oggetto di studi specifici }\end{array}$ & $\begin{array}{l}\text { Continuando a tradição (P-1D) } \\
\text { RO } \\
\text { Presentare in maniera più approfondità ed } \\
\text { estensiva quella ricerca }\end{array}$ \\
\hline
\end{tabular}

Ao sistematizar certas práticas da língua em uso, constatamos que o modelo proposto por Aranha (1996), conforme podemos verificar no quadro anterior, é totalmente aplicável às introduções de artigos científicos em língua italiana. Há, porém, certas peculiaridades não somente em cada introdução, como também ao considerarmos os dois grupos de revistas, possivelmente devido à divergência de retórica característica de cada autor e à influência dos temas e da área de pesquisa científica.

Os elementos linguísticos utilizados na construção das introduções, juntamente com a descrição da organização das estruturas argumentativas podem ser muito úteis para propósitos pedagógicos, uma vez que somente o domínio da língua italiana não é suficiente para a construção de gêneros coerentes com a comunidade discursiva da qual se quer fazer parte.

\section{CONSIDERAÇÕES FINAIS}

A análise de dez introduções de artigos científicos de duas revistas italianas permitiu apontar as evidências linguísticas e a estrutura argumentativa do discurso acadêmico em duas diferentes áreas de conhecimento - biológica e tecnológica - bem

Cadernos do IL. Porto Alegre, n. ${ }^{o}$ 38, junho de 2009. p. 108-129. http://www.seer.ufrgs.br/cadernosdoil/ 
como verificar a aplicabilidade do modelo CARS, proposto inicialmente por Swales (1997) e revisto por Aranha (2006).

Os dados mostraram que o modelo se aplica também às introduções escritas na língua italiana, porém, corroborando as afirmações de Hemais e Biasi-Rodrigues (2005), não se trata de aplicações fiéis, uma vez que o modelo é uma simplificação da realidade, conforme coloca Bloor (1998, apud HEMAIS; BIASI-RODRIGUES, 2005), o que torna inevitável adaptações que vão ser delimitadas dentre vários fatores pelas tradições, crenças e convenções de cada comunidade.

Notamos, portanto, a influência significativa da área de conhecimento não somente na escolhas linguísticas, mas, principalmente, na seleção e na organização dos movimentos e passos no processo de construção da introdução. Ambas não chegam a subverter o modelo proposto, mas devem, necessariamente, ser explicitadas para que professores e alunos compreendam a maneira como determinado gênero se organiza, levando em consideração todos os fatos que determinam e influenciam sua construção.

São necessárias, assim, pesquisas que investiguem a retórica das introduções, principalmente em língua italiana, em que desconhecemos trabalhos nesta área, a fim de facilitar o processo de ensino e aprendizagem dos gêneros. Com este texto, pretendemos trazer uma pequena contribuição a essa área, uma vez que, a nosso ver, o primeiro passo para a construção do conhecimento é uma melhor compreensão do assunto que propomos investigar.

Sendo assim, acreditamos e defendemos, como Aranha (2007), o entrelaçamento das ciências, pois, havendo maior e mais intensa investigação em áreas diversas que se interligam, uma construção muito mais ampla e enriquecedora de conhecimentos científicos auxiliará o trabalho do professor e poderá fornecer aparatos linguísticos e estruturais para que as teorias possam ser mais facilmente compartilhadas, não ficando restritas apenas ao âmbito acadêmico.

\section{REFERÊNCIAS}

ARANHA, S. A argumentação nas introduções de trabalhos científicos da área de Química. 1996. Dissertação (Mestrado em Lingüística Aplicada ao Ensino de Línguas) Pontifícia Universidade Católica de São Paulo, São Paulo, 1996.

. The search for more appropriate models for teaching academic writing. Revista $\overline{d o ~ G E L}$, São Paulo, v. 4, n. 2, 2007, p. 97-115.

BAZERMAN, C. Gêneros textuais, tipificação e interação. Tradução de Judith Chambliss Hoffnagel. 2. ed. São Paulo: Cortez, 2006.

BHATIA, V. Analysing genre: language use in professional settings. Nova York: Longman, 1993.

CAI, K. R. Comparação de introduções de artigos científicos publicados em inglês, espanhol e português produzidos por falantes nativos. Relatório de iniciação científica. São José do Rio Preto: Universidade Estadual Paulista, 2008.

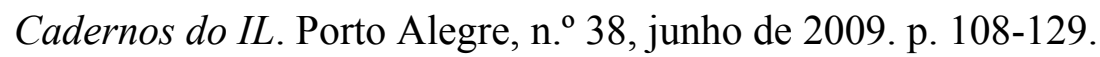


DUSZAK, A. Academic discourse and intellectual styles. Journal of Pragmatics, v. 21, n. 3, p. 291-313, 1995.

FIGUEIREDO, D. C.; BONINI, A. Práticas discursivas e ensino do texto acadêmico: concepções de alunos de mestrado sobre a escrita. Linguagem em (Dis)curso, v. 6, n. 3, 2005.

HEMAIS, B.; BIASI-RODRIGUES, B. A proposta sócio-retórica de John M. Swlaes para o estudo de gêneros textuais. In: MOTTA-ROTH, D.; BONINI, A.; MEURER, J. L. (org). Gêneros: teorias, métodos, debates. São Paulo: Parábola Editorial, 2005.

MARCUSCHI, L. A. 1946 - Produção Textual, análise de gêneros e compreensão. São Paulo: Parábola Editorial, 2008.

- Gêneros textuais: definição e funcionalidade. In: DIONÍSIO, A. P.; MACHADO, A. R.; BEZERRA, M. A. (orgs.). Gêneros Textuais \& Ensino. 2.ed. Rio de Janeiro: Lucerna, 2002.

MOTTA-ROTH, D. Escritura, gêneros acadêmicos e construção do conhecimento, s.d.. Disponível em: <<http://www.ufsm.br/labler/publi/escritur.htm $>>$. Acesso em maio 2009.

ROJO, R. Gêneros do discurso e gêneros textuais. Questões teóricas e aplicadas. In: MOTTA-ROTH, D.; BONINI, A.; MEURER, J. L. (org.). Gêneros: teorias, métodos, debates. São Paulo: Parábola Editorial, 2005.

SWALES, J. M. Genre analysis: English in academic and research settings. Cambridge: Cambridge University Press, 1990.

. Research Genres. Cambridge: CUP, 2004.

SWALES, J. M.; FEAK, C. Academic writing for graduate students. Michigan: University of Michigan Press, 1994.

Cadernos do IL. Porto Alegre, n. ${ }^{\text {o } 38, ~ j u n h o ~ d e ~ 2009 . ~ p . ~ 108-129 . ~}$ 